\title{
Clonidine in the Treatment of Tardive Dyskinesia: A Case Review
}

\author{
Vikram Khot, MD \\ Medical College of Wisconsin Affiliated Hospitals, Milwaukee, Wisconsin \\ Jean Goodwin, MD, MPH \\ Medical College of Wisconsin Affiliated Hospitals, Milwaukee, Wisconsin \\ Geoff Wandry, MD \\ Medical College of Wisconsin Affiliated Hospitals, Milwaukee, Wisconsin
}

\section{Follow this and additional works at: https://jdc.jefferson.edu/jeffjpsychiatry \\ Part of the Psychiatry Commons \\ Let us know how access to this document benefits you}

\section{Recommended Citation}

Khot, MD, Vikram; Goodwin, MD, MPH, Jean; and Wandry, MD, Geoff (1989) "Clonidine in the Treatment of Tardive Dyskinesia: A Case Review," Jefferson Journal of Psychiatry. Vol. 7 : Iss. 1 , Article 5.

DOI: https://doi.org/10.29046/JJP.007.1.002

Available at: https://jdc.jefferson.edu/jeffjpsychiatry/vol7/iss $1 / 5$

This Article is brought to you for free and open access by the Jefferson Digital Commons. The Jefferson Digital Commons is a service of Thomas Jefferson University's Center for Teaching and Learning (CTL). The Commons is a showcase for Jefferson books and journals, peer-reviewed scholarly publications, unique historical collections from the University archives, and teaching tools. The Jefferson Digital Commons allows researchers and interested readers anywhere in the world to learn about and keep up to date with Jefferson scholarship. This article has been accepted for inclusion in Jefferson Journal of Psychiatry by an authorized administrator of the Jefferson Digital Commons. For more information, please contact: JeffersonDigitalCommons@jefferson.edu. 


\title{
Clonidine in the Treatment of Tardive Dyskinesia: A Case Review
}

\author{
Vikram Khot, M.D. \\ Jean Goodwin, M.D., M.P.H. \\ Geoff Wandry, M.D.
}

\section{INTRODUCTION}

Over the past several years, a number of cardiovascular preparations have become widely used in psychiatry. For example, propranolol, introduced for its anti-anginal properties, is now used for stage-fright, lithium tremor and neuroleptic induced akathisia $(1,2)$. Calcium channel blockers are expected to prove useful in the treatment of bipolar affective disorders $(3,4)$.

Clonidine exemplifies the rapidity and variety with which a cardiovascular agent has been applied to psychiatric syndromes. Clonidine, a centrally acting anti-hypertensive drug with both alpha-1 and alpha-2 adrenergic agonistic properties, has already been used in the treatment of narcotic withdrawal, benzodiazepine withdrawal, Tourette's syndrome, akathisia, depression, chronic schizophrenia and acute mania, as well as in tardive dyskinesia $(1,5,6)$.

The therapeutic effectiveness of clonidine in tardive dyskinesia was initially reported by Freedman and co-workers and by Nishikawa and co-workers $(7,8)$. Tardive dyskinesia is a term applied to a group of involuntary movement disorders usually involving the oro-facial region, but also affecting limbs and trunk. This disorder, on average reversible in over one-third of all patients in whom neuroleptics are discontinued (9), is a persistent neurologic complication induced by longterm neuroleptic treatment. Nishikawa and co-workers treated 29 such patients with clonidine; results at 4 years follow up showed that 75 percent showed at least moderate improvement; full resolution occurred in 50 percent of the cases (10). Onset of improvement occurred within 3 to 7 days of initiating clonidine treatment. The present communication reports an additional case in which videotapes documented the movement disorder before and during clonidine treatment. Abrupt cessation of clonidine resulted in enhanced dyskinetic movements.

\section{CASE REPORT}

The patient is a 29 year old white single student admitted voluntarily to a psychiatric hospital after three days of auditory and visual hallucinations and vague feelings of depersonalization. The patient's first contact with psychiatry occurred 5 years previously when he was diagnosed as being "psychotically depressed" with symptoms of depersonalization and derealization. The present 
admission was his fifth psychiatric hospitalization. He had been treated with a variety of antipsychotics; three years prior to admission he was stabilized on 10 $\mathrm{mg}$ of thiothixene per day. This was discontinued one year prior to admission. However, three months prior to admission he was restarted on thiothixene at doses ranging from $15 \mathrm{mg}$ to $40 \mathrm{mg}$ per day as a result of re-emergence of psychotic symptoms. The case was further complicated by the presence of complex partial seizures, which were reported to have occurred 2-3 times a week; electroencephalogram showed paroxsymal bursts of diffuse theta waves.

According to his mother, abnormal movements of the upper extremities, facial grimacing, and tic-like movements had become obvious six months prior to admission. The movements were continuous and not seizure related. Once the diagnosis of tardive dyskinesia was suspected, the doses of thiothixene were gradually decreased. The patient had abused numerous substances, including cocaine, LSD, alcohol and marijuana since adolescence. There was no current substance abuse. It is important to note that the patient's brother was also taking antipsychotic medication. He also exhibited a movement disorder characterized by dystonic posturing, but refused further neuropsychiatric evaluation of these movements.

Initially the patient exhibited a mildly constricted affect with dysphoric mood. His speech was coherent, although digressive. He described feelings of derealization and depersonalization; there were no hallucinations or disruptive behaviors. The patient's general physical and neurologic exam was normal (aside from abnormal movements). Neither hypotonia nor incoordination was present. He was noted to have continuous stereotyped involuntary choreoathetoid movements in the upper extremeties including grimacing and bucco-lingual masticatory movements. Blood chemistries were within normal limits, including normal thyroid function tests. A magnetic resonance scan was normal.

Repeat electroencephalography showed generalized theta wave slowing. Differential diagnostic possibilities that were ruled out included Huntington's chorea, Tourette's syndrome, amphetamine intoxication, brain tumor and torsion dystonia. The consulting neurologist confirmed the diagnosis of tardive dyskinesia. The consultant also recommended an empirical trial of anticonvulsants because the psychic symptomatology in conjunction with the nonspecific EEG abnormalities were so suggestive of complex partial seizures. The patient was thus treated with valproic acid.

The patient's thiothixene was gradually reduced to $5 \mathrm{mg}$ once daily. At this point the patient's movements were videotaped. Clonidine 0.1 milligram twice daily was initiated. Thereafter on every second day, clonidine was increased by a tenth of a milligram and thiothixene was decreased by one milligram a day. The dosage of clonidine was stabilized at 0.5 milligrams a day, in part because postural hypotension developed at this point. Thiothixene was then discontinued. After three days on this dosage, repeat videotaping and a repeat AIMS rating was done. Significant clinical improvement was noted. Table One shows the blind ratings by two observers and AIMS scores (11) (done by two treating 
physicians) obtained before treatment was initiated, after three days of treatment and after 10 days of treatment. The patient was discharged, but rehospitalized three weeks later after having abruptly discontinued all his medications. The "after cessation" column on Table 1 shows the AIMS ratings for his movement disorder at that time. He refused to be videotaped, but the treating physicians rated his movements as having returned to pre-treatment levels of severity.

The patient refused further treatment of his movement disorder or clonidine treatment. However, he did continue to take valproic acid which had been started for his complex partial seizures, a total of 1250 milligrams in divided doses.

\section{DISCUSSION}

Accurate diagnosis is the first problem in any study of the treatment of tardive dyskinesia. The differential diagnosis is extensive and includes Huntington's chorea, Tourette's syndrome, L-dopa induced chorea, senile chorea, Wilson's disease, torsion dystonia, viral encephalitis and amphetamine intoxication. Also, in the absence of a history of exposure to anti-psychotic medication or neuroleptics used as antiemetics, there does not appear to be, as yet, any biochemical or clinical way to establish whether a choreiform or dystonic movement is "tardive" or is a reflection of a primary neurologic disorder (12). A further complication is that on the average tardive dyskinesia is reversible in only a third of all patients in whom neuroleptics are discontinued and tends to

TABLE 1.

Ratings of Patient's Movement Disorder Before, During, and After Treatment of Clonidine

\begin{tabular}{ccccc}
\hline Raters & Baseline & $\begin{array}{c}\text { Maximum } \\
\text { Treatment } \\
\text { (after 3 days) }\end{array}$ & $\begin{array}{c}\text { After Cessation } \\
\text { of Clonidine Dose } \\
\text { (after 10 days } \\
\text { of treatment) }\end{array}$ & $\begin{array}{c}\text { (3 days after } \\
\text { withdrawal) }\end{array}$ \\
\hline TP 1 (AIMS) & 3 & 2 & 1 & 3 \\
TP 2 (AIMS) & 3 & 2 & 1 & 3 \\
CN 1 (BGR) & 3 & 2 & 1 & \\
CN 2 (BGR) & 3 & 2 & 1 & \\
\hline
\end{tabular}

TP 1 and TP 2 = Treating Psychiatrists aware of treatment status who rated the patients using the AIMS schedule.

$\mathrm{CN} 1$ and $\mathrm{CN} 2$ = Consulting Neurologists blind to treatment status who rated videotapes.

AIMS scores are summed from 9 specific observations, each scaled 0 to $4 ; 0$ (none), 1 (minimal), 2 (mild), 3 (moderate), and 4 (severe).

Blind global ratings (BGR) by consulting neurologists are scaled; 4 (extremely severe), 3 (moderately severe), 2 (moderate), 1 (mild) and 0 (absent). 
persist at an even level of severity in the remaining two-thirds of the patients (9).

In this case, the presence of an affected sibling and EEG abnormalities caused us to suspect the possibility of a primary rather than drug-related movement disorder. However, consultants viewing the videotapes have diagnosed tardive dyskinesia uniformly. We also considered the possibility that the patient's AIMS scores improved because of neuroleptic withdrawal rather than the use of clonidine; however, the rapid time course of improvement and the return of abnormal movements once clonidine was withdrawn argue against this explanation.

Tardive dyskinesia is thought to result from chronic blockade of receptors by neuroleptics leading to supersensitization of post synaptic striatal dopamine receptors (13). Neuroleptics block dopamine receptors thus preventing dopamine from acting on post-synaptic neurons. The post-synaptic cell responds to this blockade by making new dopamine receptors, after which the cell becomes supersensitive to dopamine. This supersensitivity is said to relate to tardive dyskinesia; however, nothing in this hypothesis explains why only a few patients subjected to long term dopamine receptor blockade develop dyskinetic movements. The hypothesis does predict, however, that when receptors are unblocked, for example when neuroleptics are discontinued, post-synaptic cells will have an increased response and choreiform or dystonic movements will appear or increase. This is consistent with clinical observations, such as the very typical onset after discontinuation of medication $(14,15)$, as occurred in this case. If doses of neuroleptics are increased, the new receptors are blocked and tardive dyskinesia will abate temporarily.

A more recent hypothesis proposes that noradrenergic as well as dopaminergic overactivity is important in tardive dyskinesia (10). Clonidine in low doses appears to have anti-noradrenergic effects reducing noradrenergic function by stimulating pre-synaptic noradrenergic neurons, which ultimately down-regulates the noradrenergic axis as receptors decrease. The doses of clonidine used in this study and by Nishikawa and coworkers (10) were comparable to low doses used in the treatment of hypertension. Similarly, the three day delay in onset and in improvement of tardive dyskinesia after clonidine was started parallels the one to three day interval before anti-hypertensive effects are seen when clonidine is used for hypertension. These parallels suggest that clonidine may act in tardive dyskinesia, as has been postulated for its action in hypertension, by down-regulating noradrenergic transmission.

\section{CONCLUSION}

Previous reports indicate that over fifty percent of cases of tardive dyskinesia respond with improvement to treatment with the alpha noradrenergic agonist, clonidine. This report adds another case in which both rapid improvement on initiation and rapid exacerbation on discontinuation of clonidine 
treatment were documented. The postulated mechanism of action of clonidine-down-regulation of noradrenergic activity by decreasing functional receptor supersensitivity - meshes with the postulated mechanism for tardive dyskinesia, receptor supersensitivity. Clonidine has an advantage over some other agents used to treat tardive dyskinesia, in that it has few side effects. Postural hypotension, the major side effect in our experience, usually can be controlled by stabilizing the dosage, as in this case, because even low dosages are effective in decreasing abnormal movements.

Discontinuation of neuroleptics or lowering the dosage as much as clinically possible remains the mainstay of treatment of tardive dyskinesia. This case illustrates the importance of some of the measures recommended for prevention of tardive dyskinesia: 1) use of neuroleptics only when there is a specific indication and 2) the need to consider discontinuation of neuroleptics when target symptoms do not respond after six months.

However, as in this case, there is a role for treatments which reduce the severity of the movement disorder, even when withdrawal of neuroleptics is the major intervention. Even in those patients who respond to neuroleptic withdrawal, abnormal movements may persist.

Because tardive dyskinesia has a high prevalence (15-20\% of those exposed to a neuroleptic agent for more than one year) and a high incidence (2-5\% for the first few years of neuroleptic maintenance) (16), there is need for more research on treatment methods in this disorder. No treatment to date uniformly benefits dyskinesias in all patients (17). The work to date with clonidine indicates that finding effective new treatments can also give clues as to the basic biology of the disorder.

\section{REFERENCES}

1. Johnson M: Psychiatric uses of anti-adrenergic and adrenergic blocking drugs. J Nerv Mental Dis 172:123-132, 1984

2. Lipinski, Jr, JF, Zubenko GS, Cohen BM, et al: Propranolol in the treatment of neuroleptic-induced akathisia. Am J Psychiatry 141:412-415, 1984

3. Brotman AW, Farhadi AM, Gelenberg AJ: Verapamil treatment of acute mania. J Clin Psychiatry 47:136-138, 1986

4. Gitlin MJ, Weiss J: Verapamil as maintenance treatment in bipolar illness: A case report. J Clin Psychopharmacol 4:341-343, 1984

5. Keshavan MS, Crammer JL: Clonidine in benzodiazepine withdrawal. Lancet 1:1325-1326, 1985

6. Adler LA, Angrist B, Peselow E, et al: Clonidine in neuroleptic-induced akathisia. Am J Psychiatry 144:235-236, 1987

7. Freedman R, Bell J, Kirch D: Clonidine therapy for coexisting psychosis and tardive dyskinesia. Am J Psychiatry 137:629-630, 1980

8. Nishikawa T, Tanaka M, Koga I, et al: Tardive dyskinesia treated with clonidine. Kurume Med 27:209-210, 1980

9. Jeste DV, Wyatt RJ: Therapeutic strategies against tardive dyskinesia. Arch Gen Psychiatry 39:803-816, 1982 
10. Nishikawa T, Tanka M, Tsuda A, et al: Clonidine therapy for tardive dyskinesia and related syndromes. Clin Neuropharm 7:239-245, 1984

11. National Institute of Mental Health: Abnormal involuntary movement scale. In Guy W (ed): ECDEU Assessment Manual. Rockville, MD. US Department of Health, Education and Welfare 1976

12. Nausieda P: Movement disorders encountered in psychiatry. Unpublished article, 1984

13. Gerlach J, Reisby N, Randup A: Dopaminergic hypersensitivity and cholinergic hypofunction in the pathophysiology of tardive dyskinesia. Psychopharmacology (Berlin) 34:21-25, 1974

14. Jacobson G, Baldessarini RJ, Manschrek T: Tardive and withdrawal dyskinesia associated with haloperidol. Am J Psychiatry 131:910-913, 1974

15. Escobar JI, Tuason VB: Neuroleptic withdrawal dyskinesia. Psychopharmacology Bulletin 15:71-74, 1979

16. Baldessarini RJ: Clinical and epidemiological aspects of tardive dyskinesia. J Clin Psychiatry 46:8-13, 1985

17. Tardive dyskinesia: Summary of task force report of the American Psychiatric Association. Am J Psychiatry 137:1163-1172, 1980 